\title{
EL MODERNISMO EN ESPAÑA: ALGUNOS CONCEPTOS CRÍTICOS
}

\author{
ROSA FERNÁNDEZ URTASUN \\ Universidad de Navarra
}

\begin{abstract}
Dar nombre a una corriente literaria significa tanto como reconocer que dentro de una determinada evolución de la cultura se ha establecido un cambio cualitativo que hace de ese momento algo singular y distinto con respecto al que le precede y al que le sigue. Estos cambios suelen responder a evoluciones reales que se han verificado en la filosofía, en la ciencia, en los modos estéticos. Son habitualmente de carácter muy amplio y, al menos en el ámbito europeo, se desarrollan de manera simultánea o sucesiva en las principales áreas lingüísticas. Así ha ocurrido con las corrientes que se han ido continuando desde la formación de las lenguas romances hasta nuestros días.

En el siglo $\mathrm{Xx}$, la conciencia crítica sobre el propio quehacer y la rapidez de los procesos culturales han hecho que las denominaciones se multipliquen de manera muy fragmentada. En el caso de España, el sistema generacional ha favorecido una serie de subdivisiones que responden más a determinados hechos exteriores - de la historia política del paísque a cambios efectivos en el discurrir interno de la literatura. Sin embargo, también durante el siglo que acabamos de cerrar, junto con esas denominaciones se han mantenido algunas de carácter más general, que corresponden a movimientos de ámbito internacional. La historiografía las había favorecido menos, pero cada vez están cobrando más importancia. Así sucede con el término de «modernismo», que había quedado como movimiento de transición, difundido durante unos pocos años en España por una serie de autores extranjeros (Darío, Martí) y cuya aportación se afirmaba fundamentalmente esteticista. Hoy en día, a la vista del calado internacional que ha tenido esta corriente, se tiende en el ámbito hispánico a replantear el concepto que lo define, los ámbitos que engloba ${ }^{1}$.
\end{abstract}

\footnotetext{
${ }^{1}$ La revista Bulletin of Spanish Studies ha dedicado recientemente su volumen LXXIX (números 2-3, correspondientes a los meses de marzo a mayo de 2002) a una revisión 
Creo que vale la pena detenerse en este punto de la difusión internacional del término «modernismo» antes de pasar a los intentos de definición. ¿Puede decirse realmente que el «modernismo» hispánico es equivalente al ingles «Modernism»? ¿Es una misma corriente internacional o son dos corrientes distintas? La crítica mayoritaria contemporánea parece querer agruparlos. Sin embargo, el largo peso de la tradición que dividió modernismo y 98 , escindiendo así la literatura española de la europea ${ }^{2}$, se sigue manteniendo hoy en algunos casos, a veces por el peso de la inercia y en otras ocasiones por defender que la postura que trata de unificarlas es un intento servilista por parte de los países latinos de asimilarse a las corrientes dominantes de la cultura central norteamericana ${ }^{3}$. Tan legítimo es mantener las divisiones como buscar la unidad, pero creo que sería interesante poder pergeñar algunos conceptos críticos que nos permitieran descubrir en la literatura de la primera mitad del siglo XX una línea general de pensamiento, como lo fueron en otros momentos el espíritu renacentista, barroco o romántico. Estas generalizaciones se concretan en último término según la idiosincrasia particular de cada país, se desarrollan casi siempre de manera escalonada y no simultánea en distintos lugares, pero nos permiten tener esos puntos de referencia comunes que tan interesantes resultan para poder entender la literatura de otras culturas diferentes a la nuestra.

En mi acercamiento al modernismo voy a tener en cuenta la literatura hispánica peninsular, pero mi perspectiva, precisamente por lo que acabo de exponer, es más amplia. Creo que muchas de las características del modernismo hispánico son trasladables al modernismo entendido según el concepto anglosajón. Me gustaría que este trabajo pudiera servir para acercar ambos puntos de vista en un camino que pudiera llegar a una asimilación de ambas manifestaciones.

teórica y crítica del modernismo hispánico. Tanto la introducción de Nelson R. Orringer (pp. 133-148) como los artículos de C. Christopher Soufas, jr. («Julius Petersen and the Construction of the Spanish Literary Generation», pp. 247-262) y C. A. Longhurst («Coming in from the Cold: Spain, Modernism and the Novel», pp. 263-283) insisten en la necesidad de olvidar el concepto de «generación del 98» y de integrar los conceptos de modernismo y Modernism para dar a los escritores de la primera mitad del siglo XX el sitio que les corresponde dentro de la tradición literaria europea contemporánea. En su contribución («When Was Modernism in Spanish-American Fiction?», pp. 395-409), Donald Shaw enfatiza la necesidad de una nueva definición del modernismo y amplía el problema anteriormente citado al ámbito hispanoamericano. En el caso de Shaw podemos ver cómo este artículo supone un acercamiento a la postura más general desde posiciones más conservadoras (The Generation of 1898 in Spain, 1975).

${ }^{2}$ Esta perspectiva crítica, como es bien sabido, la comenzó el mismo Azorín y fue continuada por críticos tan respetables como Pedro Salinas, Pedro Laín Entralgo, Guillermo Díaz Plaja, Ángel Valbuena o José Carlos Mainer.

3 Cfr. Blanco Aguinaga, Carlos, Sobre el modernismo, desde la periferia, pp. 17-22. 


\section{MODERNISMO LITERARIO Y MODERNISMO TEOLÓGICO}

Dentro del ámbito hispánico, el nombre «modernismo» nació con esta vocación generalista. Así al menos lo ve Juan Ramón Jiménez, quien explica:

«El modernismo, el movimiento modernista, empezó en Alemania a mediados del siglo XIX y se acentuó mucho a fines del siglo XIX. Fue muy importante entre los teólogos que empezaron ese movimiento. (...) Este movimiento pasó a Francia por los teólogos (...) y de ahí pasó a los Estados Unidos. (...) Entonces, ese nombre, Modernismo, aparece en la literatura, y no aparece en todos los países simultáneamente. (...) Es decir, lo que corresponde a lo que en Hispanoamérica, en España, en Rusia, en Alemania, le llaman modernismo literario es lo que en Francia se llama parnasianismo y simbolismo. (...) Es decir, que el Modernismo es un movimiento general, como el Renacimiento» ${ }^{4}$.

Entró en escena con una carga semántica que va más allá de lo que la tradición historiográfica literaria parece querer asignarle. La consolidación de esta nomenclatura en otros ámbitos de la cultura distintos al artístico (muy especialmente en teología y filosofía) habla de dimensiones de pensamiento superiores a las que se le conceden en los estudios que destacan como lo más relevante y casi lo único determinante la faceta de renovación estilístico-formal.

El espléndido trabajo coordinado por el profesor de Llera sobre Religión y literatura en el modernismo español me exime de la necesidad de demostrar aquí con detalle las relaciones que de hecho hubo entre literatos y teólogos. Pero me permite al mismo tiempo afirmar que es necesario entrar en categorías filosóficas y no sólo literarias para poder dar una definición correcta de este movimiento. Llera demuestra que los principales autores del modernismo literario conocían el modernismo teológico y concebían ambos como un proyecto común de modernización. Lo cual no quiere decir que todos los modernistas españoles aceptaran el modernismo teológico. Con esta afirmación me limito a constatar que ambos formaban parte de un mismo ambiente o de una misma preocupación. El propio Juan Ramón Jiménez explicaba el modernismo literario en función del teológico: «es muy importante también señalar que el modernismo tiene un origen teolójico y que la poesía llamada modernista, es decir, la parnasiana y la simbolista, pretendían y Rubén Darío lo dice, unir la tradición, española en este caso (léase, el dogma), a las innovaciones formales (léase descubrimientos científicos modernos)» ${ }^{5}$. Del mismo modo que el modernismo teológico quería dar un paso más allá, por ejemplo, en el estudio de la

\footnotetext{
${ }^{4}$ JIMÉNEZ, Juan Ramón, El modernismo. Apuntes de curso (1953), p. 74.

5 JiMÉNEZ, Juan Ramón, El modernismo..., p. 5.
} 
Sagrada Escritura para adaptarlo a las nuevas corrientes históricas, el modernismo literario quería a su vez dar un salto cualitativo con referencia a la tradición formal anterior ${ }^{6}$.

Pero ¿de dónde surge esta necesidad de cambio? En época de crisis son muchas las causas que provocan un desplazamiento en la forma de afrontar la realidad. En este caso, creo que se puede decir que el giro modernista fue el último gran esfuerzo de la modernidad por asegurar un conocimiento objetivo de la realidad antes de que se impusiera relativismo absoluto de la postmodernidad. El enfoque subjetivo de las gnoseologías post-cartesianas facilitó, sin duda, un mayor conocimiento de los procesos interiores del ser humano. Pero esa racionalidad absoluta que buscaba provocar certezas, al estar basada en la subjetividad, no sólo dio lugar a una paradójica desconfianza en la razón, sino también a grandes lagunas en cuanto a dimensiones del hombre que van más allá de los desarrollos lógico-discursivos. No es extraño por tanto que el modernismo surgiera entre las élites intelectuales teológicas y artísticas, en el ámbito de quienes que desconfían de la razón como único instrumento para conocer realidades trascendentes.

\begin{abstract}
«Acción y contemplación parecen contradecirse, como voluntarismo y racionalismo, intuición y ciencia. En cambio son tres de los muchos binomios contrapuestos que podemos utilizar para explicar el modernismo como rechazo de la época precedente y como camino abierto a soluciones que, usando métodos de conocimiento diferentes, poco tendrían en cuenta la objetividad y la racionalidad como saber modelo de la comunidad humana. El modernismo tenderá tanto hacia el misticismo unamuniano como hacia la acción voluntarista barojiana. De cualquier modo ambos métodos coinciden en el rechazo del ser y del pensar de la élite decimonónica»?
\end{abstract}

El modernismo teológico, decía Juan Ramón Jiménez, trata de adaptar el catolicismo a los recientes descubrimientos científicos. Este criterio lo aplicaron los teólogos modernistas especialmente en lo que concierne al desarrollo de la filología y la historia en relación con la Sagrada Escritura. Los estudios bíblicos fueron objeto así de un claro avance en cuanto al rigor con el que se trataban los textos en cuanto tales. Pero al mismo tiempo los modernistas proponían un subjetivismo casi absoluto en cuanto a su interpretación. Buscaban de este modo una relación más cercana y directa entre Dios y el alma, en la cual la emotividad y el sentimiento tendrían un papel principal. Esta misma dualidad se observa en las artes. Los literatos modernistas, por lo general, son exquisitos en el conocimiento y trabajo de la técnica literaria. Por otro lado, buscan que, precisamente a través de

\footnotetext{
${ }^{6}$ Salto que no implica rechazo, ni mucho menos desconocimiento (cfr. D'Ors, Miguel, «Joyas nuevas de plata vieja», pp. 232 y ss.).

${ }^{7}$ LlERA, Religión y literatura en el modernismo español (1902-1914), p. 92.
} 
la belleza así creada, el lector pueda escapar de la alienación del materialismo y el capitalismo utilitaristas a través del contacto con la dimensión espiritual de la vida. Se trata de una necesidad teórica que se transfiere al ámbito vital y llega a adquirir matices existenciales. En concreto querían escribir una literatura tal que fuera capaz de hacer descubrir la gratuidad de la realidad (su belleza) en el mundo industrializado y deshumanizado que iba a dar lugar y siguió a la primera guerra mundial. No había en ello principalmente un motivo estético sino ético: consideraban misión de los escritores transmitir esa nueva mirada sobre el mundo. Pero tenia obvias y necesarias repercusiones formales: la ruptura con lo precedente se produjo porque pronto se puso en evidencia que el arte anterior no servía para este propósito. La literatura realista y naturalista era cientificista y positivista, por lo tanto poco espiritual. La romántica era idealista, absoluta. Resaltaba el «yo» del poeta, pero en unas dimensiones cósmicas, alejadas del «yo personal e intimista del modernismo» ${ }^{8}$. La ilustrada era demasiado racional y cualquiera de las anteriores ajena al espíritu moderno. Había que escribir para el hombre que estaba apareciendo en las grandes ciudades, en los suburbios industriales, para los burgueses de mentalidad mercantilista, para los hombres del siglo XX.

\section{PRECEDENTES ESTÉTICOS}

Es tradicional afirmar que las bases del modernismo hispánico hay que buscarlas en las corrientes poéticas que dominan la segunda mitad del siglo XIX francés: el parnasianismo y el simbolismo. Ambas corrientes representan los extremos entre los que va a pendular el modernismo. Son movimientos sobradamente conocidos, pero considero necesario esbozar en una línea lo más general de su estética para poder avanzar en el concepto de modernismo. Los parnasianistas reaccionan contra el romanticismo sentimental y descuidado con una poesía impasible, de una implacable perfección formal. Su lema, resumen de su doctrina estética, es «el arte por el arte». Suponen una recuperación temática y formal del clasicismo grecorromano, se interesan por la mitología nórdica y aportan todos los elementos exquisitos que tanta importancia tendrán en la apariencia esteticista del modernismo. También es contribución suya el cambio de proporción con respecto al romanticismo: la belleza de su naturaleza, de sus ciudades, de sus objetos, es perfecta en cuanto a la composición pero humana, cotidiana en cuanto a la magnitud ${ }^{9}$. Por último, la aportación formativa que su-

\footnotetext{
${ }^{8}$ LLERA, Religión y literatura..., p. 95.

9 Así por ejemplo, «la nature, si importante, si exaltée de toutes les façons chez les romantiques (...) est remplacée par la campagne, familière, quotidienne, pratique, source
} 
ponen en cuanto la dimensión de trabajo que tiene toda obra literaria es valiosísima. La confianza en el arte como modo de conocimiento hubiera sido imposible sin esta alta estima de las reglas internas de la composición literaria.

En la escuela parnasiana se formaron los principales autores simbolistas. Pero en éstos el interés por la belleza toma un cariz diferente. Se podría decir que la poesía parnasiana es positivista, materialista y sensual. Frente a ella, el simbolismo es un movimiento de signo espiritual, en el que la realidad es manifestación de otra realidad ulterior, escondida, que es la verdadera. Los simbolistas recuperan la presencia del poeta desde un punto de vista diferente al parnasiano, van a descubrir la importancia de su papel como profeta, su visión privilegiada capaz de hacernos reconocer a nuestro lado las huellas del verdadero mundo.

La manera de acceder a éste es a través de analogías y correspondencias, de los estados afectivos provocado por las imágenes ${ }^{10}$. Estas imágenes, a diferencia del romanticismo, ya no van a ser abstractas, mentales, sino sensibles, especialmente pictóricas y musicales. El centro del subjetivismo que - herencia del racionalismo - estaba en la inteligencia, pasa ahora a la sensibilidad: «le but, conscient ou le plus souvent inconscient, de l'artiste symboliste est de suggérer, c'est-à-dire de provoquer en l'autre l'émotion, le sentiment, l'état d'âme qu'il a ressentis lui-même (...) Le processus, quoi qu'en ait voulu dire Valéry, est affectif bien plus qu'intellectuel» ${ }^{11}$. Por tanto, vamos a encontrarnos ante una poesía individualista, intimista, de sugerencias e intuiciones, de símbolos ambivalentes. La imagen confiere a la obra no sólo una significación desconocida sino una pluralidad de significaciones absolutamente indispensable.

Así explica Mallarmé, que participó de las dos escuelas, sus diferencias fundamentales:

«La contemplation des objets, l'image s'envolant des rêveries suscitées para eux, sont le chant: les Parnassiens, eux, prennent la chose entièrement et la montrent: par là ils manquent de mystère ; ils retirent aux esprits cette joie

de plaisirs très concrets (...). La ville, c'est toujours la grande cité, bien sûr, c'est toujours Paris, mais ayant perdu ses dimensions mythiques» (Decaunes, Luc, La Poésie parnassienne. Anthologie, p. 31).

${ }^{10}$ La base filosófica de esta propuesta la explica Manuel Álvarez Ortega: «concuerda con la metafísica subjetiva, reflejo de las teorías kantianas, que no admiten otra realidad que el mundo de las ideas y declara la imposibilidad de acceder al mundo exterior por otras vías que no sean las que su imagen proporciona en nosotros. Por otro lado, concuerda también con las concepciones de la psicología, que concede cada vez más un lugar de excepción al subconsciente en la vida del espíritu» (Poesía simbolista francesa, p. 18).

"PEYRE, Henri, La littérature symboliste, p. 9. Esta reflexión se puede afirmar también en cierto sentido del modernismo teológico, ya que en última instancia su rebelión fue más vital que racional. 
délicieuse de croire qu'ils créent. Nommer un objet, c'est supprimer les trois quarts de la jouissance du poëme qui est faite de deviner peu à peu: le suggérer, voilà le rêve. C'est le parfait usage de ce mystère qui constitue le symbole: évoquer petit à petit un objet pour montrer un état d'âme, ou, inversement, choisir un objet et en dégager un état d'âme, par une série de déchiffrements» ${ }^{12}$.

Donde el parnasianista veía en la técnica y la palabra un instrumento privilegiado para cincelar realidades perfectas, el simbolista busca el misterio del alma al que sólo puede acceder a partir de un objeto recreado poéticamente. De ahí su interés por una espiritualidad de corte gnóstico en la que frecuentemente se confunden lo esotérico (en algunos casos cábala y espiritismo ${ }^{13}$ ) y el sueño. De ahí también que el simbolismo conjugue de este modo dos características aparentemente distantes pero que con tanta frecuencia aparecen unidas en literatura: la sensualidad y la mística.

\section{LA CUESTIÓN DE LA BELLEZA}

De esta comparación me interesa deducir un punto. Si se considera que ambas corrientes forman el principio del modernismo, es porque hay algún un rasgo de fondo en el que coinciden y que permite aunar sus postulados. ¿Cuál es este rasgo? ¿De qué modo estas influencias de índole opuesta se pueden convertir en complementarias? Pienso que el catalizador que desde los presupuestos parnasianistas y simbolistas dará lugar a una nueva corriente literaria es el papel nuclear que tiene en ambos la idea de belleza. Este concepto se irá convirtiendo en el eje alrededor del cual se articularán las vidas y las obras de los autores modernistas.

He puesto de relieve al comienzo de este trabajo que el modernismo surge en España en primer lugar como movimiento filosófico y teológico. Me ha parecido importante insistir en este dato porque pienso que es el que otorga al concepto de belleza durante estos años una profundidad propia de estas ciencias. No es casual que precisamente a finales del XIX cambiara la definición de esta voz en el DRAE: la edición de 1884 deja de explicarse en términos formales y se expresa por primera vez de modo filosófico al definir la belleza como como «propiedad de las cosas que nos

12 MALlarmé, Stéphane, Euvres complètes, p. 869

${ }^{13}$ Los caminos que conducen a esta degradación de lo místico son fáciles de deducir: «se si sviluppa in religione dell'avvenire o dell'umanità, il misticismo implica una filosofia della storia e perciò spinge a una decisione circa questa forma filosofica; può del resto costringere a considerazioni non del tutto piacevoli circa il bisogno di ideologie facili, sentimentali e consolanti che sembra manifestarsi soprattutto nei paesi economicamente più sviluppati» (FORNI ROSA, Guglielmo, Il dibattito sul modernismo religioso, p. 101). 
hace amarlas, infundiendo en nosotros deleite espiritual». Y precisa: «esta propiedad existe en la naturaleza y en las obras literarias y artísticas» ${ }^{14}$. Este cambio obedece a un giro en la percepción que de esta idea hay en esos momentos en los ambientes intelectuales. En efecto, los autores modernistas cuando piensen en la belleza no van a tomar como referencia una apariencia de las cosas sino una propiedad que les es esencial. Y que además se predica en primer lugar de lo material: la naturaleza creada (en el sentido propio del participio) y la naturaleza transformada por el hombre con un fin estético. La belleza no se atribuye en primera instancia a las ideas, los valores o las acciones: en todos estos elementos podemos hablar de belleza por analogía. La belleza se encuentra primariamente en aquellas cosas que pueden captarse por los sentidos. Por eso para los intelectuales este concepto tendrá un gran valor a la hora de justificar su obra de creación.

Lo distintivo de la belleza es que hace lo material amable con «deleite espiritual». Esta es la segunda parte de la definición y la que le da su verdadera dimensión. Lo material, en cuanto tal, no puede ser amable, ya que lo material puede dar placer pero no amor ${ }^{15}$. Esto significa que en el juicio estético, cuando decimos que algo es bello, estamos descubriendo, junto a la singularidad de lo continuo, algo que lo trasciende, que es capaz de dar plenitud y que por ello reclama la adhesión de la voluntad ${ }^{16}$.

${ }^{14}$ En efecto, esta definición aparece por vez primera en el DRAE de 1884. La edición anterior, de 1869 la define como: «hermosura, beldad. Dícese de las personas y las cosas». Este tipo de descripción formal se encuentra actualmente en diccionarios que pertenecen a tradiciones distintas de la hispana (en la que el DRAE tiene siempre un gran peso magisterial). Así podemos verlo por ejemplo en el Oxford Dictionary: «combination of shape, color, etc., that pleases the senses».

15 «Respecto del objeto del amor, o aquello a lo que se tiende cuando se aspira a la felicidad, cabe decir que en el orden objetivo, no en el de la conciencia, no puede ser algo material porque algo material es siempre algo particular que extingue un deseo particular pero no todos los deseos. (...) Aquello a lo que se refiere radical y absolutamente el amor ha de ser tal que una vez sobrevenido se alcance la propia plenitud, de modo que siga habiendo amor pero no deseos» (ARREGUI, Jorge Vicente y Jacinto CHOZA, Filosofía del hombre. Una antropología de la intimidad, p. 245).

${ }^{16}$ Resultan muy clarificadoras a este respecto las siguientes palabras de $\mathrm{M}^{\mathrm{a}}$ Antonia Labrada: «Lo característico de un juicio estético en el que se afirma que algo es bello, es la afirmación de algo como único e irrepetible, es decir, como singular. (...) Ello es debido al particular engarce que se da en el juicio estético entre la inteligencia y la voluntad. (...) El juicio estético es en primera instancia y sustancialmente un acto de la inteligencia; en él se pone en juego la capacidad discriminatoria del entendimiento; por ello se hablar de juicio (...) Lo que el entendimiento enjuicia o discrimina es un principio de unidad (...) que comparece como unicidad, es decir, como una forma de unidad única e irrepetible.

La percepción de algo como único e irrepetible indica la presencia de la voluntad en el juicio estético. Lo único es lo en sí mismo valioso, lo bueno que comparece con un carácter de plenitud y reclama la adhesión de la voluntad» (Estética, pp. 16-17). 
La belleza es aquella propiedad de los seres, por tanto, que nos permite percibir en ellos una dimensión espiritual.

Este descubrimiento supone para los modernistas el reconocimiento de una vocación de evidentes orígenes románticos. Desde principios del XIX encontramos en los ambientes artísticos una urgente necesidad por recuperar la magia y la belleza de la vida que el racionalismo de la Ilustración había relegado a un segundo plano. Quizá en un primer momento aparece con más peso el aspecto subjetivo de esta necesidad. Sin embargo, como ha quedado expuesto, el parnasianismo reacciona contra la grandilocuencia vana y descuidada de algunos autores secundarios buscando una belleza objetiva, incluso técnica, que considera superior. El simbolismo da un paso más allá afirmando que la belleza más perfecta no es la de la apariencia de las formas, sino la que es reflejo de una belleza interior ${ }^{17}$. El racionalismo deja de lado aquellos aspectos de la persona (imaginación, fantasía, vida sobrenatural) que no son demostrables por principios lógicos. Durante este tiempo los artistas se sienten llamados a la misión de devolver al mundo la pasión de la belleza necesaria para vivir una vida verdadera. En un momento en el que aparentemente sólo la ciencia y la técnica se presentan como criterios de verdad, los poetas van a volver su mirada hacia la belleza como el elemento sin duda más válido para orientar en el orden de la acción. Desde otro punto de vista se podría decir que lo que plantean es justificar el arte como una necesidad vital y su obra como un compromiso profundo con la realidad que les rodea.

A este respecto querría poner de relieve una carencia del movimiento que considero de importancia. Los modernistas se preocupan por investigar a qué responde esta dimensión espiritual, cuál es esa realidad misteriosa a la que la belleza apunta. Esta pregunta les lleva desde el misticismo visionario de Swedenborg (gran inspirador de los simbolistas) hasta el ocultismo o el modernismo teológico. En todos los casos se busca una espiritualidad que reaccione contra el racionalismo imperante, que evite cualquier tipo de dogma y que permita una relación directa con el «más allá» ${ }^{18}$. Sin embargo, los testimonios que encontramos en sus obras dejan

\footnotetext{
17 Justificaron esta afirmación los simbolistas en la doctrina de Swedenborg, a quien tomaron por maestro y quien afirma, por ejemplo, que «así como cambian los estados interiores de amor y sabiduría de los ángeles, así cambian también los estados de las diversas cosas que los rodean y son visibles a sus ojos; pues la apariencia de las cosas que rodean a los ángeles está en función de las cosas que están en su interior» (Del cielo y del infierno, p. $195-\$ 156-$-).

18 «El mundo espiritual de la poesía es el mundo de la pura heterodoxia o, mejor, de la pura herejía. Todo verdadero poeta es un hereje, y el hereje es el que se atiene a postceptos y no a preceptos, a resultados y no a premisas, a creaciones, o sea poemas, y no a decretos, o sea dogmas. Porque el poema es cosa de postcepto, y el dogma, cosa de precepto» (UnAmuno, Miguel de, «Poética», en Gerardo Diego, Poesía española contemporánea, p. 60). Estas palabras de Unamuno demuestran su gran cercanía al moder-
} 
ver que la búsqueda no consigue llegar a una respuesta válida. El subjetivismo inmanente y agnóstico de los presupuestos impide la trascendencia que la belleza refleja. Ante esta situación las reacciones de los artistas son diferentes. Algunos, como Unamuno o Machado, mantienen la tensión de la búsqueda hasta el final. Otros, como Baroja y Valle-Inclán, se refugian en un escepticismo moderado, que no les impide tampoco seguir escribiendo (que es su manera propia de buscar). En los casos más extremos, lo que sucede es que el medio se convierte en fin, y la belleza acaba siendo divinizada en sí misma, como ocurre con Juan Ramón Jiménez. La consecuencia lógica de esta situación es que en el postmodernismo desaparecerá la confianza en la belleza como modo de alcanzar el sentido, y con ella el último reducto de la esperanza que puso la modernidad en la capacidad del hombre para alcanzar verdades, inmanentes o trascendentes, por sí solo.

\section{OTRAS NOCIONES CRÍTICAS DERIVADAS}

Han sido los mismos escritores los que han ido abriendo el camino de los estudiosos para llegar a este punto. En el quehacer artístico de la modernidad se advierte - se podría aventurar que desde Kant, en quien la filosofía del arte se convierte en crítica- cómo los autores integran dentro de sus obras muchos elementos reflexivos. La función de este metadiscurso es asegurar una crítica correcta, en la que sea el arte el que abra el contexto y no el contexto el que trate de determinar el significado de la obra ${ }^{19}$. En los escritos de los modernistas abundan los «credos poéticos», las «poéticas», los «retratos» y «autorretratos»; en definitiva las consideraciones sobre la vida y la literatura integradas en el mismo contexto de la ficción. En cierto sentido se podría decir que esta dimensión reflexiva siempre ha estado presente en el arte, pero la diferencia es que en estos momentos los autores la quieren hacer explícita precisamente en el interior de la obra. Esto significa que no sólo van a escribir prólogos críticos en los que den razón de su escribir - lo que ya de por sí es una novedadsino que a lo largo de su obra de ficción vamos a encontrar una dimensión metaliteraria que va a ser distintiva de la literatura del siglo XX. Esta conciencia del propio quehacer que se refleja en los textos es una característica del modernismo que se mantendrá también en el postmodernismo.

En algunos casos extremos estas reflexiones son tan abundantes que la

nismo teológico. Por otra parte, manifiesta que lo importante en el poema no es la idea preconcebida sino aquello que se descubre en el propio hacerse del arte: aparece la belleza como orientación.

19 Algunas de las nociones de este último punto del artículo las he desarrollado con más profundidad en mi libro Poéticas del modernismo español. Para esta relación entre artistas y críticos, cfr. p. 13 a 19. 
obra queda convertida en un libro de género incierto, mezcla de crítica, autobiografía y ficción. Creo que estas obras se encuentran entre las más características y significativas de los autores modernistas. Al analizarlas podemos descubrir en ellas una serie de puntos comunes y recurrentes que podrían definirse como los conceptos básicos del pensamiento modernista. Esencialmente podrían reducirse a tres: la relación entre realidad y ficción que se establece en cualquier obra literaria, la conciencia de la propia identidad que tienen los autores (su autocomprensión en concreto como escritores) y la percepción del tiempo presente como exigencia de sentido. Son a su vez algunos de los puntos que la modernidad ha subrayado con más fuerza, aunque lógicamente se podría hablar de otros. Pienso que la centralidad del concepto filosófico de belleza es la perspectiva necesaria y adecuada para comprender estos aspectos del modernismo que, en última instancia, se derivan de él.

El primero de ellos, el que más directamente hace explícita la idea de belleza que he expuesto más arriba, es el de la relación entre realidad y ficción. La pregunta clave es para qué escribir. Por qué hacer de la literatura la razón de su vida. Baroja se pregunta:

\begin{abstract}
«¿Para qué ocuparse de las aventuras de un loco que no ha existido como Don Quijote? ¿A qué hablar de los pensamientos de un neurasténico que tampoco ha existido como Hamlet? ¿Qué valen los sufrimientos supuestos del joven Werther ante un dolor de muelas agudo, ni las vicisitudes falsas de Robinson Crusoe ante las de un señor que ha perdido el tren? Es, sin disputa alguna, mucho más importante que Hamlet, que Don Quijote y que Werther, un manual de cocina, al menos si es práctico, y la gente que piensa así debe preferir el calarse dignamente el gorro blanco de cocinero que no el birrete con pompón de colores del profesor» ${ }^{20}$.
\end{abstract}

El tono irónico del fragmento tiene su razón de ser en la última frase, que esconde un ataque velado a las teorías expuestas por Ortega en Ideas sobre la novela. Baroja no se responde a sí mismo en ese momento, se trata de una pregunta aparentemente retórica. Pero a lo largo de La intuición y el estilo sí da una respuesta, y lo hace apelando al concepto modernista de belleza. Siguiendo una tradición muy anterior (se remonta a Aristóteles) considera que la literatura «se halla más cerca de la constante espiritual de un país» ${ }^{21}$ que la historia, porque «la historia, como la política, está sometida a los vientos que corren; en cambio, la literatura, al parecer siempre mucho más subjetiva y mucho más apasionada, que parece mariposear sobre la vida, tiene una raíz en ésta más fuerte y más segura» ${ }^{22}$. Por eso puede también afirmar que «no hay, seguramente, obra de economía o de

${ }^{20}$ BAROJA, Pío, La intuición y el estilo, p. 207.

${ }^{21}$ BAROJA, Pío, La intuición y el estilo, p. 74.

22 BAROJA, Pío, La intuición y el estilo, p. 80. 
hacienda que dé una idea del estado social de España en el tiempo como Don Quijote. A pesar de ser una ficción, es más realista que todas las obras de los sabios del tiempo» ${ }^{23}$. La mirada de la belleza es una mirada que singulariza y trasciende, que es por tanto capaz de integrar en sí esos aspectos vitales que las ciencias experimentales no captan. Baroja confía en el poder gnoseológico de la literatura, en su valor como medio para conocer la realidad, para - una vez conocida - entender cuál es el sentido de la vida y en concreto de la suya. Por eso también en la ficción se puede encontrar un proyecto. El escritor se hace a sí mismo y a sus lectores en su escritura, a través de su novela. Esta será una idea fundamental en la obra de Unamuno:

«Y así cuando les cuento cómo se hace una novela, o sea, cómo estoy haciendo la novela de mi vida, mi historia, les llevo a que se vayan haciendo su propia novela, la novela que es la vida de cada uno de ellos. $\mathrm{Y}$ desgraciados si no tienen novela. Si tu vida, lector, no es una novela, una ficción divina, un ensueño de eternidad, entonces deja estas páginas, no me sigas leyendo» ${ }^{24}$.

Se puede observar en este fragmento cómo la relación entre literatura y ficción está muy ligada con la noción de identidad. En efecto, la comprensión de sí mismos en estos autores responde directamente a una conciencia vocacional. Su vida es su misión, ser escritores, y por eso se hacen y se cumplen al mismo tiempo que se hace la obra. Pero, a diferencia de lo que se suele pensar, no se trata de una identidad cerrada en sí misma: la obra se hace para los demás. En este contexto se entiende que tenga una gran importancia la idea de salvación, que hay que interpretar en la acepción diluida que de este concepto tiene el modernismo teológico ${ }^{25}$. Unamuno expresa su preocupación por la salvación al hablar de la responsabilidad del escritor por construir su propia vida y la de su nación: «no quieren saber que mis cátedras, mis estudios, mis novelas, mis poemas son política» ${ }^{26}$. Y

${ }^{23}$ BAROJA, Pío, La intuición y el estilo, p. 91. Esta idea aparece en otras obras suyas: «Don Quijote, a quien Cervantes quiso dar un sentido negativo, es un símbolo de la afirmación de la vida. Don Quijote vive más que todas las personas cuerdas que le rodean, vive más y con más intensidad que los otros. El individuo o el pueblo que quiere vivir se envuelve en nubes como los antiguos dioses cuando se aparecían a los mortales. El instinto vital necesita de ficción para afirmarse» (BAROJA, Pío, El árbol de la ciencia, p. 175).

${ }^{24}$ UnAmuno, Miguel, Cómo se hace una novela, p. 57.

25 En el modernismo teológico la pregunta por la salvación se soslaya: «La questione della salvezza individuale è una questione metafisica della quale non possiamo dire nulla; ma il contributo di sforzi e di sacrifici che noi portiamo all'evolversi dell'umanità viene comunque conservato in quel regno di giustizia e di pace che l'umanità attende, e che era solo prefigurato nell'immagine mitica del Regno di Dio» (FORNI RosA, Guglielmo, Il dibattito sul modernismo religioso, p. 132). De ahí las grandes tensiones de escritores como Unamuno, el más modernista entre los autores españoles.

${ }^{26}$ Unamuno, Miguel, Cómo se hace una novela, p. 89. 
en un plano superior: «no hay otra política que la de salvar en la historia a los individuos. Ni el asegurar el triunfo de una doctrina, de un partido, acrecentar el territorio nacional o derribar un orden social vale nada como no sea para salvar las almas de los hombres individuales» ${ }^{27}$. Por eso afirmará que lo importante en la novela es el para qué:

«Cómo se hace una novela, ¡bien!, pero ¿para qué se hace? (...) Para hacerse el novelista. ¿Y para qué se hace el novelista? Para hacer al lector, para hacerse uno con el lector. Y sólo haciéndose uno el novelador y el lector de la novela se salvan ambos de su soledad radical. En cuanto se hacen uno se actualizan y actualizándose se eternizan» ${ }^{28}$.

La novela se escribe para alcanzar la eternidad, para inmortalizar al autor y al lector. Como se ve, la salvación en Unamuno no tiene que ver con la religión o la moral sino la necesidad de permanencia, lo importante es sobrevivir en el tiempo.

Llegamos así al tercer aspecto. Tanto las relaciones de la ficción con la realidad como la noción de identidad aparecen en la obra de arte ligadas a la noción de tiempo. En cuanto a las primeras, el problema es claro: el arte es temporal, también la historia que nutre el arte es pasajera, y sin embargo el arte trasciende. Si el arte le sirve al hombre para llevar más allá su mirada habitual es porque hay en él una dimensión espiritual, que, como tal, está llamada a eternidad. La tensión entre ambos aspectos es cuestión nuclear en todo arte. En este aspecto, la doctrina de Bergson fue fundamental para entender la importancia de la intuición en el conocimiento y la noción de tiempo absoluto. Pueden verse sus huellas en estas palabras de Machado:

«En este año de su Antología (1931) pienso, como en los años del modernismo literario (los de mi juventud), que la poesía es la palabra esencial en el tiempo. La poesía moderna (...) viene siendo hasta nuestros días la historia del gran problema que al poeta plantean estos dos imperativos, en cierto modo contradictorios: esencialidad y temporalidad.

El pensamiento lógico, que se adueña las ideas y capta lo esencial, es una actividad destemporalizadora. Pensar lógicamente es abolir el tiempo, suponer que no existe, crear un movimiento ajeno al cambio, discurrir entre razones inmutables» 29 .

${ }^{27}$ UNAMUNO, Miguel, Cómo se hace una novela, p. 53.

${ }^{28}$ UnAmuno, Miguel, Cómo se hace una novela, p. 112.

29 MACHADO, Antonio, «Poética», en Gerardo Diego, Poesía española contemporá$n e a$, p. 149. Es inevitable pensar en Bergson al leer estas palabras. Confróntense con las siguientes del filósofo francés: «¿Cuál es el objeto del arte? Si la realidad pudiera llegar directamente a nuestros sentidos y a nuestra conciencia (...) creo que el arte sería inútil, o más bien que todos seríamos artistas (...). Escucharíamos (...) en el fondo de nuestras almas la melodía ininterrumpida de nuestra vida interior. [Pero existe un velo entre nosotros y nuestra conciencia], un grueso velo para la mayoría de los hombres, pero velo ligero, casi transparente para el artista y para el poeta. ¿Quién ha colocado ese 
Esta doble perspectiva hace a los modernistas reflexionar sobre la importancia del tiempo presente como tiempo absoluto. El tiempo presente es aquél en el que se comienza la obra, en el que el escritor se enfrenta con la página en blanco. En él está incluido el pasado porque la experiencia de la realidad es imprescindible para poner en marcha la narración: es lo que justifica el relato de hechos ya acontecidos:

«Con los ojos vueltos al pasado, yo lograba romper el enigma del Tiempo. Encarnados en imágenes, veía yuxtaponerse los instantes, desgranarse los hechos de mi vida y volver uno por uno. Percibía cada momento en sí mismo como actual, sin olvidar la suma» ${ }^{30}$.

A su vez, este tiempo presente absoluto encierra en sí el futuro, ya que no se puede escribir si no es en una dirección. En la comprensión de la propia identidad hay un punto de referencia ineludible que es el de la muerte:

«De rato en rato me tumbo en un diván y contemplo el cielo, añil o ceniza. ¿Y por qué habrá de saltar de improviso el evento impensado? Trabajamos día tras día. Trabaja tú, pintor, y trabaja tú, poeta. Lo que caiga fuera de nuestro trabajo serán efímeros episodios. Episodios placenteros o dolorosos. Pluma en mano, pluma en las cuartillas, paliemos el dolor. ¿Dónde está nuestro Leteo? En el afán diario. $\mathrm{O}$ acaso, a través de la obra, hacemos ese dolor más delicado» ${ }^{31}$.

Azorín se refiere al Leteo para marcar, desde el principio del libro, la perspectiva de la muerte. El desprendimiento de la historia que implica el río del olvido es necesario para la disfrutar el presente eterno. Azorín entiende que el Leteo del escritor es su trabajo cotidiano, porque en él encuentra la posibilidad de sustraerse a la sujeción del pasado y la oportunidad de vivir en presente.

De este modo, entramos ya en el último aspecto que quiero resaltar en este breve repaso de algunos de los conceptos críticos del modernismo que es el de la expresión literaria. Me parece muy importante insistir de nuevo en la parte material de toda obra de arte, aspecto fundamental, como hemos visto, en el concepto de belleza. El libro, poema o narración, sólo es

velo? (...) Tenemos que vivir, y la vida exige que captemos las cosas por la relación que tienen con nuestras necesidades. (...) Vivir es aceptar de los objetos sólo la impresión de su utilidad. (...) La individualidad de las cosas y de los seres se nos escapa cada vez que no nos es útil percibirlas (...). Incluso nuestra propia individualidad se nos escapa. (...) Pero muy de vez en cuando, casi como si se distrajera, la naturaleza produce algunas almas más despegadas de la vida. [Esos son los artistas, cuya función es] apartar los símbolos prácticamente útiles [para] situarnos cara a cara con la realidad misma» (Bergson en Le Rire, citado por Blanco AguinagA, Carlos, Sobre el modernismo..., p. 39).

${ }^{30}$ VAlle-INCLÁN, Ramón M. a , La lámpara maravillosa, p. 85.

${ }^{31}$ AZORín, El escritor, p. 13. 
una obra de arte cuando efectivamente está escrito. Los autores modernistas hablan siempre de dos vertientes necesarias para la escritura de la obra. Una de ellas es el discernimiento de lo eterno en lo temporal, que el escritor capta de manera intuitiva y recibe como un don particular. No se trata de la inspiración romántica: por un lado porque ese descubrimiento no sería posible sin la atenta observación de la realidad, de donde surge siempre la obra y hacia la que va dirigida. Por otro, porque todos los autores coinciden en afirmar que esa observación sólo es eficaz cuando va acompañada del despojamiento propio, del desasimiento de los gustos particulares y las ideas personales: sólo así se descubre también en aquello que tendemos a rechazar. La belleza descubre el significado intrínseco que todas las cosas tienen por el mero hecho de existir: «el amor de todas las cosas es la cifra de la suma belleza, y quien ama con olvido de sí mismo penetra el significado del mundo» ${ }^{32}$.

La otra vertiente es la constructiva: no basta con captar la belleza de la realidad, debe también reflejarse en la obra de arte de manera que pueda ser descubierta por el lector. Esta plasmación escrita no es posible sin el esfuerzo del trabajo y sin un estricto conocimiento de las leyes literarias. Entre éstas una es fundamental: la búsqueda de la unidad. La visión del mundo que tienen los modernistas es la que corresponde a una época de crisis. Como ha quedado puesto de relieve, su compromiso con la belleza es una respuesta a la situación (económica, social, religiosa, científica) que les rodea. Su misión es construir con la narración una síntesis de lo heterogéneo en la que una realidad que perciben como caótica, desconcertante, decadente, mediocre y utilitaria deje entrever el brillo de lo singular y lo amable. No se trata de crear obras de perfección parnasianista, en las que la unidad sea un entramado sin fisuras pero externo. Se trata más bien de admitir lo fragmentario como tal, dejando simplemente adivinar el hilo que conduce el sentido. Esto habitualmente exige un gran esfuerzo por parte del lector, pero no es más que una huella de la sinceridad de su propósito de reflejar la complejidad de lo real y su sutil unidad. Los recursos técnicos que utilicen para lograrlo serán variadísimos. Conocen muy bien las leyes de la gramática y la retórica, porque saben que sólo quienes las dominan pueden manejarlas a su antojo y quebrantarlas cuando sea necesario. Sólo quien es capaz de buscar sin descanso la palabra exacta o de abandonar un hallazgo expresivo que llama demasiado la atención sobre sí mismo es capaz de conseguir la unidad necesaria para que la obra exprese un sentido que brille con la belleza de lo trascendente.

Esta confianza en la obra de ficción como descubridora de sentido fue, como decía, el último intento de la modernidad por afirmar un conocimiento verdadero basado en la subjetividad. Sus fundamentos, sin embargo, eran

${ }^{32}$ VAlLE-INCLÁN, Ramón M.a , La lámpara maravillosa, p. 66. 
muy frágiles. La confianza en las leyes de la realidad y de la ficción provenía de la fidelidad al significado que tienen las cosas en sí, que es previo a nosotros y que no puede ser otorgado. Sin embargo, esta creencia no se basaba en una trascendencia real, objetiva, sino que fue voluntarista o mística, apoyada en la subjetividad personal, en la emotividad, en un misticismo visionario o en un voluntarismo ciego. La búsqueda del más allá que permitía la belleza se quedó así en un dar vueltas al propio objeto artístico. Sin un fundamento objetivo, la belleza pronto dejó de ser considerada como un punto de apoyo. Hoy, los constructos artísticos de la postmodernidad son explícitamente artefactos, objetos que se cierran en sí mismos o que se articulan sobre la nada. Sin embargo, se siguen produciendo, y en esta misma continuidad, aunque no tenga otra finalidad aparente que demostrar que todo es absurdo, aparece siempre la búsqueda de sentido.

\section{BIBLIOGRAFÍA CITADA}

Álvarez Ortega, Manuel, Poesía simbolista francesa, Madrid, Akal, 1984.

AzoRÍn, El escritor, Madrid, Espasa-Calpe «Austral», 1952.

BAROJA, Pío, El árbol de la ciencia, Madrid, Cátedra/Caro Raggio, 1985.

BAROJA, Pío, La intuición y el estilo, Madrid, Caro Raggio, 1983.

Blanco Aguinaga, Carlos, Sobre el modernismo, desde la periferia, Granada, Comares, 1998.

D’oRS, Miguel, «Joyas nuevas de plata vieja (el modernismo como tradicionalismo)», Bulletin of Spanish Studies, LXXIX, 2-3 (2002): 229-245.

DeCAunes, Luc, La Poésie parnassienne. Anthologie, Paris, Seghers, 1977.

Fernández Urtasun, Rosa, Poéticas del modernismo español, Pamplona, Eunsa, 2002.

FORNI ROSA, Guglielmo, Il dibattito sul modernismo religioso, Roma, Laterza, 2000.

JiMÉNEZ, Juan Ramón, El modernismo. Apuntes de curso (1953), Jorge Urrutia ed., Madrid, Visor, 1999.

LABRADA, M. ${ }^{\text {a }}$ Antonia, Estética, Pamplona, Eunsa, 1998.

LLERA, Luis de (ed.), Religión y literatura en el modernismo español (1902-1914), Madrid, Actas, 1994.

LONGHURST, C. A, «Coming in from the Cold: Spain, Modernism and the Novel», Bulletin of Spanish Studies, LXXIX, 2-3 (2002): 263-283.

MACHADO, Antonio, «Poética», en Gerardo Diego, Poesía española contemporánea, Madrid, Taurus, 1962.

MAllarmÉ, Stéphane, Euvres complètes, Paris, Gallimard, 1945.

ORRINGER, Nelson R., «Introduction to Hispanic Modernisms», Bulletin of Spanish Studies, LXXIX, 2-3 (2002): 133-148.

PEYRE, Henri, La littérature symboliste, Paris, PUF, 1947.

SHAW, Donald L., «When Was Modernism in Spanish-American Fiction?», Bulletin of Spanish Studies, LXXIX, 2-3 (2002): 395-409.

SHAw, Donald L., The generation of 1898 in Spain, London, Benn, 1975.

SOUFAS JR., C. Christopher, «Julius Petersen and the Construction of the Spanish Literary Generation», Bulletin of Spanish Studies, LXXIX, 2-3 (2002): 247-262.

SWEDENBorg, Emanuel, Del cielo y del infierno, Madrid, Siruela, 2002.

Unamuno, Miguel de, «Poética», en Gerardo Diego, Poesía española contemporánea, Madrid, Taurus, 1962. 
Unamuno, Miguel de, Cómo se hace una novela, P. R. Olson ed., Madrid, Guadarrama, 1977.

VAlle-INCLÁN, Ramón M. ${ }^{a}$ del, La lámpara maravillosa. Ejercicios espirituales, F. J. Blasco Pascual ed., Madrid, Espasa-Calpe, 1995.

VICENTE ARREGUI, Jorge y Jacinto CHOZA, Filosofía del hombre. Una antropología de la intimidad, Madrid, Rialp, 1992. 


\title{
RESUMEN
}

El modernismo en España: algunos conceptos críticos, por Rosa Fernández Urtasun.

En este artículo se propone una descripción del modernismo español que pueda servir para entender este movimiento como parte de la corriente general de la cultura occidental de la primera mitad del siglo XX que se conoce en el ámbito anglosajón con el nombre de Modernism. Para ello aparece como fundamental la noción de belleza. Esta noción por una parte une en sí características heredadas del parnasianismo y del simbolismo. Por otra, tiene una dimensión trascendente propia del modernismo filosófico y teológico contemporáneos al literario. Desde esa perspectiva se proponen a continuación una serie de criterios de juicio anejos al concepto de belleza tales como la metaficción, la identidad, el tiempo y la dimensión formal. Se describen de manera sumaria, a través de las palabras de destacados modernistas como fueron Unamuno, Azorín, Baroja, Valle-Inclán o Machado.

Palabras clave: Modernismo. Modernism. Belleza. Literatura. Filosofía. Teología. Metaficción. Identidad. Tiempo. Forma.

\begin{abstract}
This article offers a new understanding of Spanish «Modernismo» which places this concept in that wider trend of Western culture at the beginning of the $20^{\text {th }}$ century generally known as «Modernism» in the anglo-saxon world. Beauty is the central concept in this context; it includes characteristics inherited from the French parnasianism and symbolism and, at the same time, it involves a transcendental dimension which derives from the philosophical and theological Modernism, which is contemporary to the literary one. From this theoretical perspective, I aim to analyze a number of critical approaches derived from the concept of beauty, such as metafiction, identity, time or form. They are described briefly through the words of well-known Modernists such as Unamuno, Azorín, Baroja, Valle-Inclán or Machado.
\end{abstract}

Keywords: Modernismo. Modernism. Beauty. Literature. Philosophy. Theology. Metafiction. Identity. Time. Form. 